\title{
АНАЛИЗ ЭФФЕКТИВНОСТИ МЕТОДА СИНХРОННОГО ВОЗБУЖДЕНИЯ ФЛУОРЕСЦЕНЦИИ НЕФТЕЙ В МОРСКОЙ ВОДЕ
}

S. BABITSENKO, A. DUDELZAK, A. POROVKINA. MEREVEES SISALDUVA NAFTA FLUORESTSENTSI SUNKROONSE SKANEERIMISE MEETODI EFEKTIIVSUS

S. BABICHENKO, A. DUDELSACK and L. PORYVKINA. EXCITTATION SYNCHRONOUS SCANNING METHOD EFFICIENCY ANALYSIS FOR OIL FLUORESCENCE IN SEA WATER

\section{(Представил К. К. Ребане)}

Диагностика нефтяных загрязнений природных водных сред является актуальной экологической задачей. Современные спектрофлуориметрические методы детектирования следов нефтепродуктов в воде связаны с длительной. обработкой (экстрагированием) проб воды для выделения полициклических ароматических углеводородов (ПАУ). В натуральных пробах воды флуоресценция ПАУ находится на фоне свечения растворенного органического вещества (РОВ) и сигнала спонтанного комбинационного рассеяния (СКР) возбуждающего излучения на молекулах воды. Это обстоятельство мешает точному определению концентрации нефтяных загрязнений. В целях спектрофлуориметрического выделения сигнала флуоресценции нефтепродуктов (НП) на фоне свечения РОВ в морской воде был предложен метод, основанный на синхронном сканировании возбуждения (MCB) флуоресценции $\left[{ }^{1}\right]$. Спектральное фракционирование одной из компонент сложной смеси осуществляется с помощью одновременного (синхронного) изменения длин волн возбуждения и регистрируемого излучения с постоянным спектральным интервалом $\Delta$ между ними, величина которого определяется правилом Стокса для данной компоненты $\left[{ }^{2}\right]$.

Настоящая заметка посвящена результатам численных экспериментов по моделированию спектров флуоресценции двухкомпонентной смеси НП и РОВ, выполненных для оценки эффективности МСВ при селективном и синхронном возбуждениях.

В случае одномасштабных спектров интенсивность флуоресценции двухкомпонентной смеси на длине волны максимума флуоресценции POB $\lambda_{22}$ при селективном возбуждении в максимуме поглощения нефти $\lambda_{1}$ имеет вид:

$$
I\left(\lambda_{22}\right)=\eta_{1}\left(\lambda_{1}\right) I_{1}\left(\lambda_{22}\right)+\eta_{2}\left(\lambda_{1}\right) I_{2}\left(\lambda_{22}\right)
$$

где $\eta_{1}, \eta_{2}$ - весовые коэффициенты, определяющие эффективность возбуждения; $I_{1}$ и $I_{2}$ - интенсивность флуоресценции НП и РОВ при оптимальном селективном возбуждении. Интенсивность синхронного спектра на длине волны $\lambda_{22}$ при спектральном интервале, равном стоксову сдвигу $\Omega_{1}$ для НП (оптимальный сдвиг для выделения сигнала НП), выражается соотношением

$$
I^{s}\left(\lambda_{22}\right)=\eta_{1}\left(\lambda_{1}\right) I_{1}^{s}\left(\lambda_{22}\right)+\xi \eta_{2}\left(\lambda_{1}\right) I_{2}^{s}\left(\lambda_{22}\right),
$$


где $\dot{I}_{1}{ }^{s}, \dot{I}_{2}{ }^{s}$ - интенсивность синхронных сигналов НП и РОВ для оптимальных спектральных сдвигов $\Delta_{1}$ и $\Delta_{2}$ соответственно. Фактор $\xi$ характеризует степень подавления интенсивности сигнала флуоресценции РОВ при использовании МСB:

$$
\xi=\exp \left\{-\left(x^{2}-\Lambda^{2}\right) / 2 \delta_{2}^{2}\right\}
$$

где $x=\Omega_{1}-\Omega_{2}-$ разность стоксовых сдвигов НП и РОВ; $\Lambda$ - расстояние между максимумами флуоресценции НП и $\mathrm{POB} ; \delta_{2}-$ полуширина спектра возбуждения РОВ. При типичных параметрах спектров, наблюдаемых в эксперименте для исследованных нефтепродуктов в морской воде, छ имеет значение в пределах 0,1-0,6.

Ширина линии флуоресценции модельной двухкомпонентной смеси при использовании МСB определяется выражением:

$$
\Delta \lambda^{2}=\frac{\left(A_{r} \delta_{1}^{2}+A_{2} \delta_{2}^{2}\right)+\delta_{1} \delta_{2} A_{1} A_{2}\left[\left(\delta_{1}-\delta_{2}\right)^{2}+(x-2 \Lambda)^{2} / 2\right]}{\left(\delta_{1} A_{1}+\delta_{2} A_{2}\right)},
$$

где $A_{i}=\exp \left\{-\left(\Omega_{i}-\Delta\right)^{2} / 4 \delta_{i}^{2}\right\} ; \Omega_{i} \quad$ - стоксовы сдвиги нефти $(i=1)$ и $\mathrm{POB}(i=2)$. Минимум полуширины синхронной линии наблюдается при условии $\Delta=\Omega_{1}$.

В расчетах на ӘВМ спектры возбужденкя и излучения задавались суперпозицией гауссовых кривых с характерными параметрами, соответствующими реальным значениям. Спектры излучения двухкомпонентной смеси при селективном возбуждении $\lambda=280$ пм в максимуме поглощения нефти (кривая $a$ ) и при синхронном возбуждении (кривые $6, \quad в$, г) приведены на рис. 1. Интенсивности сигналов $I_{\text {Скр }}, I_{\text {нп }}$ и $I_{\text {ров }}$ относятся друг к другу как $0,25: 0,5: 0,5$. Выделение сигнала СКР воды осуществляется при $\Delta=30$ нм; $\Delta_{1}=55$ нм характеризует присутствие нефти, а РОВ выделяется при $\Delta_{2}=170$ нм.

Численно исследованы зависимости поведения крутизны, ширины, асимметрии, удельного интенсивностного вклада флуоресценции нефти в обычном и синхронном спектрах. Проведен сравнительный анализ стандартного отклонения полного и синхронного спектров двухкомпонентной смеси от соответствующих спектров НП (однокомпонентный образец) .

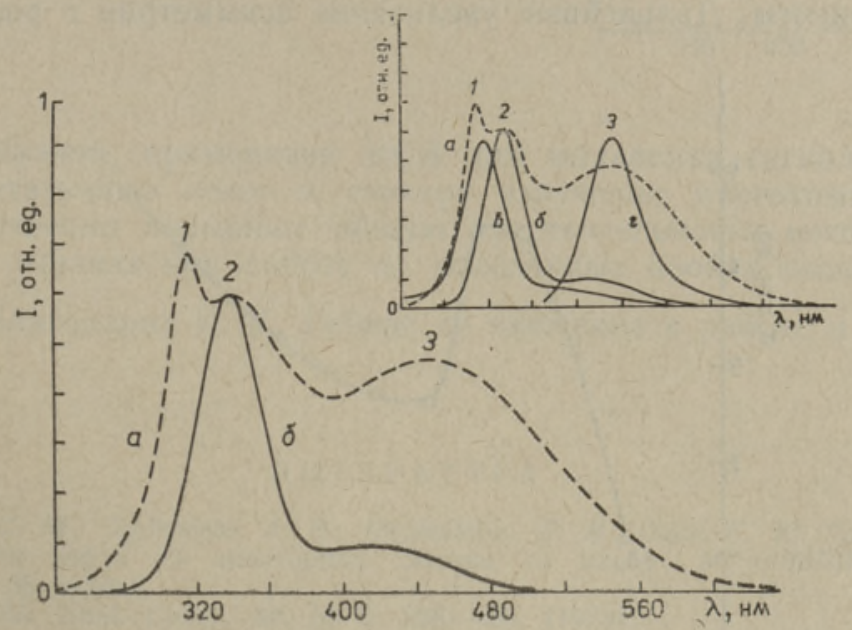

Рис. 1. Модельные спектры флуоресценции морской воды с нефтепродуктом при соотношении интенсивностей сигналов СКР, НП и РОВ $0,25: 0,5: 0,5 ; 1,2,3$ максимумы соответствующих компонент; $a-$ возбуждение с $\lambda=280$ нм; $\sigma, \varepsilon, \tau-$ синхронное возбуждение с $\Delta=55,30$ и 170 нм соответственно.

6 ENSV TA Toimetised. F* M 31988 
Расчетные характеристики полос флуоресценции модельной смеси нП и РОВ

\begin{tabular}{|c|c|c|c|c|c|}
\hline $\begin{array}{c}\text { Объект } \\
\text { исследования, } \\
\text { метод }\end{array}$ & $\begin{array}{c}\text { Длина } \\
\text { волны } \\
\text { возбуж- } \\
\text { дения, } \\
\text { нм }\end{array}$ & $\begin{array}{c}\text { Спект- } \\
\text { ральный } \\
\text { сдвиғ, } \\
\text { нм }\end{array}$ & $\begin{array}{c}\text { Крутизна } \\
\text { полосы } \\
d\left(I / I_{\max }\right) / d \lambda\end{array}$ & $\begin{array}{l}\text { Отклоне- } \\
\text { ние фор- } \\
\text { мы поло- } \\
\text { сы от } \\
\text { спектра } \\
\text { НП, \% }\end{array}$ & $\begin{array}{c}\text { Асиммет- } \\
\text { рия }\end{array}$ \\
\hline$\underset{M C B}{\mathrm{H}}+\mathrm{POB}$ & & $\begin{array}{l}30 \\
35 \\
40 \\
45 \\
50 \\
55 \\
60 \\
65 \\
70 \\
75 \\
80\end{array}$ & $\begin{array}{l}0,030 \\
0,026 \\
0,031 \\
0,031 \\
0,032 \\
0,032 \\
0,032 \\
0,032 \\
0,027 \\
0,026 \\
0,029\end{array}$ & $\begin{array}{r}10,8 \\
9,9 \\
9,6 \\
9,3 \\
9,2 \\
9,4 \\
9,9 \\
10,7 \\
11,9 \\
13,3 \\
14,9\end{array}$ & $\begin{array}{l}0,252 \\
0,643 \\
0,848 \\
0,894 \\
0,526 \\
0,554 \\
0,602 \\
0,666 \\
0,748 \\
0,846 \\
0,962\end{array}$ \\
\hline НП, МСВ & & 55 & 0,017 & 0 & $-0,066$ \\
\hline $\mathrm{H \Pi}+\mathrm{POB}$ & 280 & & 0,004 & 43 & 2,420 \\
\hline
\end{tabular}

селективное

возбуждение

Использование МСВ практически на порядок увеличивает крутизну линии флуоресценции по сравнению с обычным спектром. Наибольшее значение крутизны синхронного спектра двухкомпонентной смеси наблюдалось для линии с $\Delta_{1}=55$ нм (таблица). Минимальное значение среднего отклонения полос флуоресценции жефти в присутствии POB морской воды при МСВ от сигнала нефти в отсутствие РОВ характерно для синхронного спектра с $\Delta_{1}=50$ нм $(9 \%)$. В полном спектре соответствующее отклонение составляет более $40 \%$. Явно выражена зависимость асимметрии полосы флуоресценции двухкомпонентной смеси НП и РОВ от спектрального сдвига $\Delta$ (рис. 2). Низкое значение асимметрии при $\Delta=30$ нм обусловлено достаточно симметричным сигналом СКР воды. Следующий минимум при $\Delta_{1}=(50-55)$ нм указывает на наибольшее сходство синхронной полосы с сигналом нефтяной компоненты. Дальнейшее увеличение асимметрии с ростом $\Delta$ свя-

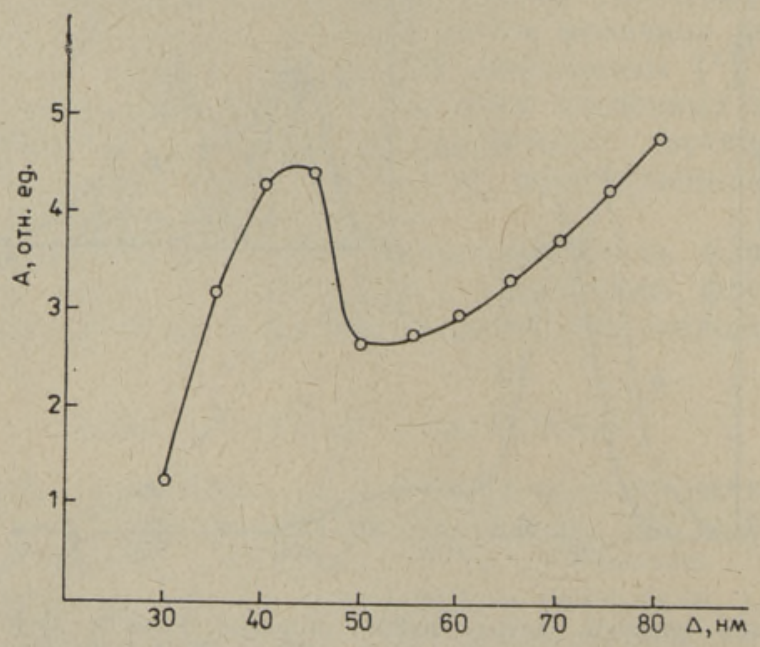

Рис. 2. Зависимость величины асимметрии модельного сигнала флуоресценции при синхронном возбуждении морской воды с нефтепродуктом от спектрального сдвига $\Delta$. 
зано с влиянием полосы излучения РОВ. В полном спектре флуоресценции морской воды с нефтью доля свечения нефти составляет $32 \%$. Применение МСВ увеличивает удельный вклад «нефтяной» составляющей в синхронном сигнале до $86-88 \%$ для промежутка значений $\Delta=$ $=(35-60)$ нм.

Закономерности, полученные в численных экспериментах, подтверждаются лабораторными и натурными исследованиями. Экспериментальный анализ образцов растворов различных сырых нефтей в морской воде показал, что при нспользовании МСВ происходит подавление сопутствующего сигнала флуоресценции РОВ с одновременным сужением полосы флуоресценции нефти (рис. 3). Концентрация нефти подбиралась так, чтобы отношение сигналов РОВ и НП было порядка единицы. МСВ был опробован в натурных условиях во время рейсов НИС «Арнольд Веймер» $(1986,1987$ гг.) и позволил регистрировать наличие остатков нефтепродуктов в концентрациях 1-2 мкл/л на фоне флуоресценции РОВ. Измерения проводились на спектрофлуориметрах СФЛ (производства ОНИЛ Рижского медицинского института) и LS-3 фирмы «Perkin-Elmer».

Рис. 3. Спектры флуоресценции сырой нефти в морской воде $(C=5$ мкл/л) при возбуждении с $\lambda=250$ нм (1) и при синхронном возбуждении с $\Delta=55$ нм (2).

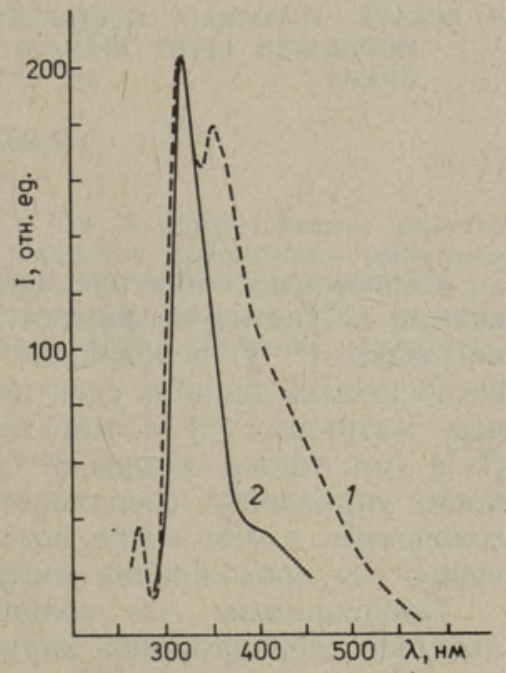

Таким образом, применение МСВ для выделения сигнала НП на фоне сопутствующих полос в спектре излучения многокомпонентной смеси существенно повышает общую чувствительность метода флуоресцентного анализа при работе на мгновенных пробах воды.

Авторы благодарят К. К. Ребане за внимание к работе и полезные обсуждения.

\section{ЛИТЕРАТ У РА}

1. Бабиченко С. М., Дудельзак А. Э., Порывкина Л. В., Саар К. Ю. Способ обнаружения нефти на акваториях. Заявка на изобр., № $4130707 / 24-25$ от 08. 10. 86. (1986).

2. Tuan Vo-Dinh. Anal. Chem., 50, № 3, 396-401 (1978).

Ннститут термофизики и электрофизики Академии наук Эстонской ССР

Специальное конструкторское бюро Академии наук Эстонской ССР
Поступила в редакцию $30 /$ XII 1987 